\title{
Approaching the immunophysiology of steroid resistance
}

\author{
Rick Bucala* \\ See related research by Wang et al., http://arthritis-research.com/content/14/3/R103
}

\begin{abstract}
Wang and colleagues have investigated a mechanistic basis for resistance to steroid therapy in systemic lupus erythematosus patients. Their examination reveals significant differences in macrophage migration inhibitory factor (MIF)-dependent expression of IKB, which is a critical cellular regulator of the broadly proinflammatory transcription factor NF-kB. Their studies also suggest that MIF may be a clinically useful biomarker in systemic lupus erythematosus and support the therapeutic targeting of MIF as a means to reduce clinical steroid resistance.
\end{abstract}

In the current issue of Arthritis Research \& Therapy, Wang and colleagues provide functional immunologic data on a molecular pathway for glucocorticoid resistance in systemic lupus erythematosus (SLE) [1]. Glucocorticoids have broad and powerful effects on the immune response and, despite the advent of biologic therapies, remain the most important and frequently used immunosuppressive agents in clinical practice [2]. Indeed, if it were not for their dose-limiting toxicity, glucocorticoids in all other respects would be ideal anti-inflammatory agents: orally absorbed, rapidly acting, and highly effective at shutting down a multitude of tissue-damaging, inflammatory pathways. Despite the clinical success of disease-modifying agents, concomitant steroid use remains an integral part of effective therapy as well as an established means for controlling disease exacerbations.

Among practitioners focused on inflammatory disorders, whether rheumatologic or nonrheumatologic, there has long been the observation that some patients respond poorly to steroids or require high doses and

*Correspondence: Richard.Bucala@Yale.edu

Section of Rheumatology, Department of Medicine, Yale University School of

Medicine, TAC S525, PO Box 208031, 300 Cedar Street, New Haven, CT 06520-8031, USA prolonged treatment for disease control. These patients expectedly suffer most from the treatment-related complications of glucose intolerance, hypertension, obesity, osteoporosis, and myopathy. Even among patients maintained on low doses, the therapeutic objective remains the absolute minimalization or discontinuation of glucocorticoids. This goal has gained additional prominence with the recognition that accelerated atherosclerosis is an attendant consequence of systemic inflammation and a major cause of morbidity and mortality in rheumatoid arthritis and SLE [3]. The contributing effects of steroidinduced glucose intolerance and dyslipidemia add to the pathophysiology of atherogenesis and prompt continued investigation into more effective steroid-sparing agents and safer approaches to immunosuppression.

Wang and colleagues provide evidence of a specific pathway for steroid resistance in patients with treatmentunresponsive SLE [1]. The authors investigated the expression and function of the immunoregulatory cytokine macrophage migration inhibitory factor (MIF), which shares a unique regulatory relationship with glucocorticoids, in the peripheral blood monocyte responses of steroid-resistant SLE patients. Experimental work had previously established that MIF counter-regulates the immunosuppressive action of glucocorticoids on proinflammatory cytokine expression [4]. In human subjects, MIF circulates in a diurnal rhythm in phase with corticosteroids, but it is rapidly upregulated by stress or inflammatory stimuli [5]. Indeed, murine MIF was first cloned from activated anterior pituitary cells [6] and a model soon emerged by which MIF, whether released from the neuroendocrine system or the immune system, acts in concert with circulating glucocorticoids to regulate the magnitude of the host inflammatory response [7]. Mice genetically deficient in MIF have an alteration in their MIF-glucocorticoid axis and lower glucocorticoid levels, which probably accounts for their developmental defect in alveolar surfactant production and lung maturation [8].

Prior experimental studies have also revealed mechanisms by which MIF counter-regulates the immunosuppressive action of glucocorticoids; these mechanisms 
include suppression of glucocorticoid-induced expression of ІкB $\alpha$, which is a cytosolic inhibitor of NF-кB [9], and suppression of glucocorticoid-induced mitogen-activated protein kinase phosphatase $[10,11]$, which inactivates the strongly proinflammatory ERK1/2, JNK, and p38 mitogenactivated protein kinase signaling pathways. Wang and colleagues investigated MIF-dependent pathways in two clinically defined cohorts of steroid-sensitive and steroidresistant SLE patients. First, they observed increased MIF levels in the steroid-unresponsive patients. Because these subjects may also have more severe underlying disease, this finding would be expected [12]. A closer study of peripheral blood monocyte responses, however, revealed higher cytosolic MIF content and higher intranuclear NF- $\mathrm{kB}$ levels in the steroid-resistant group. Experimental reduction of MIF expression in turn increased the cytosolic expression of the NF-кB inhibitor, ІкB. Conversely, exogenous MIF addition reduced glucocorticoid-induced

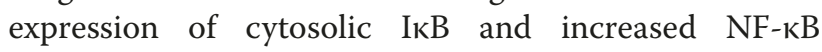
expression in the steroid-sensitive patients.

Obtaining such functional data in a significant number of clinically defined human subjects is no simple task, as those engaged in studies of human immunologic pathways can attest. One should also appreciate that this MIF-regulated pathway is unlikely to explain all features of glucocorticoid insensitivity; for instance, there is recent evidence that glucocorticoids do not affect NF- $\kappa B$ activation within plasmacytoid dendritic cells, which may be important initiators of inflammation in SLE [13]. Nevertheless, by providing mechanistic information in human cells and validating one pathway suggested by in vitro studies, Wang and colleagues' results have important implications. Their data suggest that differences in MIF expression may be an intrinsic feature of an individual's immune response, a conclusion also supported by a recent study showing significant associations between SLE clinical severity and commonly occurring, highexpression MIF alleles [14]. Circulating or cytosolic MIF also may be a useful biomarker for steroid resistance. Wang and colleagues further show inhibition of MIFdependent upregulation of ІкB by anti-MIF, which is now undergoing clinical evaluation [15]. One may thus envision the contribution of high-expression MIF alleles to the development of steroid resistance and the realistic possibility of a pharmacogenomic approach to this problem based on the utilization of MIF antagonists.

\section{Abbreviations}

IKB, NF-kB inhibitor; MIF, macrophage migration inhibitory factor; NF, nuclear factor; SLE, systemic lupus erythematosus.

\section{Competing interests}

$\mathrm{RB}$ is an inventor on patents describing the potential therapeutic utility of MIF inhibition.

\section{Published: 18 May 2012}

\section{References}

1. Wang FF, Zhu LA, Zou YQ, Zheng H, Wilson A, Yang CD, Shen N, Wallace DJ, Weisman MH, Chen SL, Lu LJ: New insights into the role and mechanism of macrophage migration inhibitory factor in steroid-resistant patients with systemic lupus erythematosus. Arthritis Res Ther 2012, 14:R103.

2. Rhen T, Cidlowski JA: Antiinflammatory action of glucocorticoids - new mechanisms for old drugs. N Engl J Med 2005, 353:1711-1723.

3. Salmon JE, Roman MJ: Subclinical atherosclerosis in rheumatoid arthritis and systemic lupus erythematosus. Am J Med 2008, 121:3-8.

4. Calandra T, Bernhagen J, Metz CN, Spiegel LA, Bacher M, Donnelly T, Cerami A, Bucala R: MIF as a glucocorticoid-induced modulator of cytokine production. Nature 1995, 377:68-71.

5. Petrovsky N, Socha L, Silva D, Grossman AB, Metz C, Bucala R: Macrophage migration inhibitory factor (MIF) exhibits a pronounced circadian rhythm relevant to its role as a glucocorticoid counter-regulator. Immunol Cell Biol 2003, 81:137-143.

6. Bernhagen J, Calandra T, Mitchell RA, Martin SB, Tracey KJ, Voelter W, Manogue KR, Cerami A, Bucala R: MIF is a pituitary-derived cytokine that potentiates lethal endotoxaemia. Nature 1993, 365:756-759.

7. Flaster H, Bernhagen J, Calandra T, Bucala R: The macrophage migration inhibitory factor-glucocorticoid dyad: regulation of inflammation and immunity. Mol Endocrinol 2007, 21:1267-1280.

8. Kevill KA, Bhandari V, Kettunen M, Leng L, Fan J, Mizue Y, Dzuira JD, ReyesMugica M, McDonald CL, Baugh JA, O'Connor CL, Aghai ZH, Donnelly SC, Bazzy-Asaad A, Bucala RJ: A role for macrophage migration inhibitory factor in the neonatal respiratory distress syndrome. J Immuno/ 2008, 180:601-608.

9. Daun JM, Cannon JG: Macrophage migration inhibitory factor antagonizes hydrocortisone-induced increases in cytosolic IkBa. Am J Physiol 2000, 279:R1043-R1049.

10. Roger T, Chanson AL, Knaup-Reymond M, Calandra T: Macrophage migration inhibitory factor promotes innate immune responses by suppressing glucocorticoid-induced expression of mitogen-activated protein kinase phosphatase-1. Eur J Immunol 2005, 35:3405-3413.

11. Aeberli D, Yang Y, Mansell A, Santos L, Leech M, Morand EF: Endogenous macrophage migration inhibitory factor modulates glucocorticoid sensitivity in macrophages via effects on MAP kinase phosphatase-1 and p38 MAP kinase. FEBS Lett 2006, 580:974-981.

12. Foote A, Briganti EM, Kipen Y, Santos L, Leech M, Morand EF: Macrophage migration inhibitory factor in systemic lupus erythematosus. J Rheumatol 2004, 31:268-273.

13. Guiducci C, Gong M, Xu Z, Gill M, Chaussabel D, Meeker T, Chan JH, Wright T, Punaro M, Bolland S, Soumelis V, Banchereau J, Coffman RL, Pascual V, Barrat FJ: TLR recognition of self nucleic acids hampers glucocorticoid activity in lupus. Nature 2010, 465:937-941.

14. Sreih AG, Ezzeddine R, Leng L, LaChance A, Yu G, Mizue Y, Subrahmanyan L, Pons-Estel B, Abelson A-K, Svenungsson E, Gunnarsson I, Cavett J, Glenn S, Zhang L, Montogomery R, Perl A, Salmon J, Alacon-Riquelme M, Harley J, Bucala R: Dual effect of macrophage migration inhibitory factor gene on the development and the severity of human systemic lupus erythematosus. Arthritis Rheum 2011, 63:3942-3951.

15. ClinicalTrials.gov: NCT01541670 [http://clinicaltrials.gov/ct2/show/ NCT01541670]

doi:10.1186/ar3820

Cite this article as: Bucala R: Approaching the immunophysiology of steroid resistance. Arthritis Research \& Therapy 2012, 14:118. 